\title{
Stochastic finite-fault modelling of strong earthquakes in Narmada South Fault, Indian Shield
}

\author{
P SENGUPTA \\ Department of Geology and Geophysics, Indian Institute of Technology Kharagpur, India. \\ e-mail: probal@gg.iitkgp.ernet.in
}

The Narmada South Fault in the Indian peninsular shield region is associated with moderate-to-strong earthquakes. The prevailing hazard evidenced by the earthquake-related fatalities in the region imparts significance to the investigations of the seismogenic environment. In the present study, the prevailing seismotectonic conditions specified by parameters associated with source, path and site conditions are appraised. Stochastic finite-fault models are formulated for each scenario earthquake. The simulated peak ground accelerations for the rock sites from the possible mean maximum earthquake of magnitude $M_{W} 6.8$ goes as high as $0.24 \mathrm{~g}$ while fault-rupture of magnitude $M_{W} 7.1$ exhibits a maximum peak ground acceleration of $0.36 \mathrm{~g}$. The results suggest that present hazard specification of Bureau of Indian Standards as inadequate. The present study is expected to facilitate development of ground motion models for deterministic and probabilistic seismic hazard analysis of the region.

\section{Introduction}

Son-Narmada Lineament is a prominent tectonic feature about $800 \mathrm{~km}$ long trending east-west, across the Indian Shield in the intraplate region of peninsular India. The seismogenesis of the tectonic regime has been observed as susceptible to moderate-to-strong seismic events as evidenced by several earthquakes namely 1927 Son-Valley $M_{W}$ 6.5, 1938 Satpura $M_{W}$ 6.4, 1957 Balaghat $M_{W}$ 5.7, 1970 Broach $M_{W}$ 5.4, and 1997 Jabalpur $M_{W}$ 5.8 (Rajendran et al 1996; Singh et al 1999a; Mandal et al 2000). The 1927 Son-Valley and 1997 Jabalpur earthquakes occurred close to each other. The fact that the two events nucleated in the lower crust (at a depth of $\sim 35 \mathrm{~km}$ ) suggests possible similar tectonic framework for large/strong events in the province. The lower-crust events were widely felt and caused significant damages with maximum intensity of VIII in MSK scale; reportedly,
28 people were killed during the Jabalpur earthquake. Several researchers have investigated the seismotectonics of the earthquakes in the region; Bhattacharya et al (1998); Singh et al (1999a, 1999b); Gahalaut et al (2004); Singh et al (2004, 2007), to name a few. These studies identified seismotectonic parameters, namely focal mechanism, stress drop, and quality factor, which constitute basic components necessary for numerical modelling of the ground-motions.

In the present study, these results are incorporated to deliver stochastic finite-fault modelling of major earthquakes in the region. The past major fault-ruptures and possible maximum earthquake are considered for the purpose. The stochastic simulation technique developed by Motazedian and Atkinson (2005) is employed in the present study. Besides relative ease in the formulation of the simulation parameters, the technique is known to be effective for high-frequency $(>0.1 \mathrm{~Hz})$

Keywords. Stochastic finite-fault models; peak ground acceleration; Narmada South Fault. 
ground-motions required for structural engineering purposes. The approach has been widely and successfully used in different parts of the globe, e.g., Atkinson and Boore (2006) in eastern North America, Nath et al (2009) in Northeast India, and Ugurhan and Askan (2010) in Turkey. It is envisaged that appropriate definitions of the seismotectonic conditions will yield effective numerical models for the strong ground-motions in the region and enable proper evaluation of the prevailing seismic hazard overcoming the paucity of earthquake recordings in the region.

\section{Seismotectonic setting of the Narmada South Fault}

Figure 1 depicts a seismotectonic map of central India; the fault patterns are adapted from Dasgupta et al (2000) and earthquake catalogue compiled by Nath et al (2011) is used. The seismicity covering period 1900-2008 as given in the map along the zone of Son-Narmada Lineament is seen aligned to the southerly dipping ENEWSW trending Narmada South Fault. The zone is bounded by Narmada North Fault to the north. Other major features include Tapti North fault, Gavilgarh fault, and Tan shear (Dasgupta et al 2000). The present study focuses on the seismically active central parts of the Indian Shield associated with 1927 Son-Valley and 1997 Jabalpur earthquakes, respectively. Both events are associated with the Narmada South Fault (Mandal et al 2000). The fault has been associated with neo-tectonic activities. The 1957 Balaghat earth- quake occurred to the south of Jabalpur, and its focal depth is unknown. On the other hand, the aftershocks of the 1997 Jabalpur earthquake clustered at a depth of 35-45 km indicating seismogenic lower crust (Kayal 2000). This conforms to the Moho depth distribution in the region, which has been observed to be within $36-47 \mathrm{~km}$ with evident unevenness in the crust-mantle boundary. The fault-plane solution of the 1997 main-shock event suggests the tectonic model for the event to reverse-faulting with left-lateral strike-slip motion. Detailed study of the major fault systems and the associated seismicity is not within the scope of the present study. Nonetheless, the seismicity in the region has been mainly associated with rift structures and sudden fault movement due to stress concentration (Kayal 2008). The prevailing stress regime has been attributed to a flexural force build up within the entire peninsular India (Bilham et al 2003). However, in the study region, possible dehydration of serpentinites at focal depth range of the main-shock event owing to high pore fluid pressure, isotropic diffusitivity, high strain rate and seismicity, and also presence of weaker mantle has been suggested (Rao and Rao 2006; Manglik et al 2008).

\section{The stochastic models of scenario earthquakes}

\subsection{The modelling technique}

Stochastic simulation is one of the expedient methods of synthesizing strong ground motion (Boore

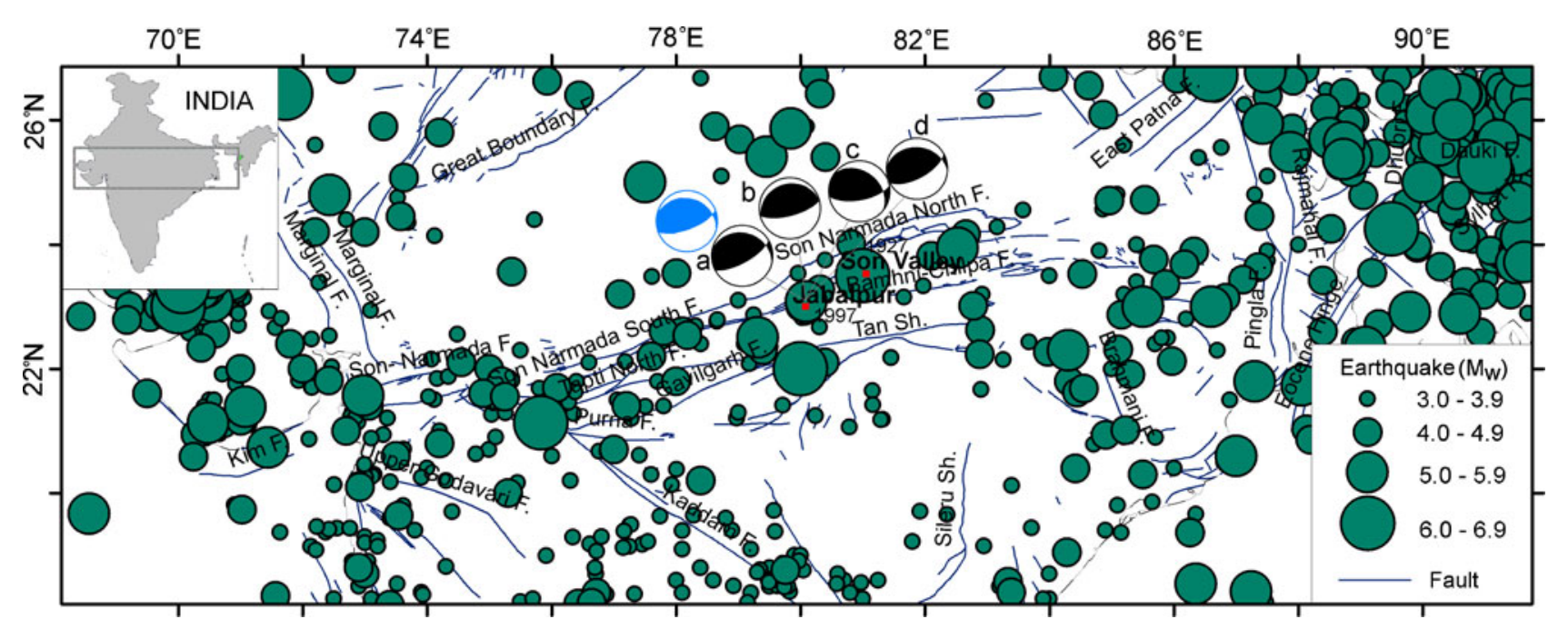

Figure 1. A seismotectonic map of central India: the fault patterns are adapted from Dasgupta et al (2000) while the beach balls for the 1997 Jabalpur earthquake given by (a) Global Centroid Moment Tensor, (b) US Geological Survey, (c) Bhattacharya et al (1998), and (d) Ramesh and Estabrook (1998). The beach ball employed in the present study is given in lighter shade. 
1983). It has been widely used to predict the ground motion around the globe where earthquake recordings are scanty. The conventional point source approximation is unable to characterize key features of ground motions from large earthquakes, such as their long duration and the dependence of amplitudes and duration on the azimuth to the observation point (source directivity). Finite source model is, thus, used to simulate the ground motion that contributes not only to the duration and directivity of ground motions; but also affect the shape of the spectra of seismic waves. The finite-fault stochastic modelling is achieved by stacking all the contributions from pointsource simulations at a number of subfaults distributed over the entire fault-rupture surface with appropriate time delay. The modelling considers fault-rupture dimensions, focal mechanism, seismic moment or magnitude, stress drop, slip distribution, hypocentral distance (or epicentral distance), focal depth, and fault pulsing percentage. The stress drop controls the amplitudes of highfrequency radiation while the fault pulsing percentage influences the relative amount of low frequency radiation (Motazedian and Atkinson 2005; Atkinson and Boore 2006). The path attenuation is quantified by the quality factor, Q-value, and geometric spreading function. The former is related to frequency dependent attenuation of spectral amplitudes while the latter accounts for variations in the seismic radiations and evidently inversely related to a factor of the distance from the source in the direction of the wave-front propagation. The decay in the spectral amplitudes at the higher frequency range is achieved by incorporating a high frequency filter in the modelling. On the other hand, the site (transfer) functions account for the influence of the local geology on the ground motion amplitudes, and it is given in terms of frequency-dependent site amplification factors.

The approach given by Motazedian and Atkinson (2005) is based on introducing dynamic corner frequencies. The major feature of the technique is the conservation of the radiated energy at high frequency at any sampling of the sub-fault size such that the relative amplitude of higher versus lower frequencies is controlled. The amplitude spectrum due to $i$ th subfault can be written as:

$$
\begin{aligned}
A_{i}(f)= & C M_{0 i} H_{i} \frac{(2 \pi f)^{2}}{1+\left(f / f_{0 i}\right)^{2}} \exp (-\pi f \kappa) \\
& \times \exp \left(-\frac{\pi f R_{i}}{\beta Q}\right) G
\end{aligned}
$$

where $M_{0 i}$ is the seismic moment of the $i$ th subfault, $R_{i}$ is the subfault distance from the observation point, and $G, \beta$ and $Q$ are geometric attenuation, shear wave velocity, and quality factor, respectively. In the above equation, the $\kappa$ filter given by Anderson and Hough (1984) defined as $\exp (-\pi f \kappa)$ is incorporated to achieve decay of the higher frequency spectra. The constant $C=$ $R^{\theta \varphi} F V /\left(\rho \pi \beta^{3}\right)$ where $R^{\theta \varphi}$ is the radiation pattern (average value of 0.55 for shear waves), $\rho$ is the density, and $F$ is the free surface amplification (2.0) while $V(=0.71)$ is the partition between two horizontal components. The seismic moment $\left(M_{0}\right)$ and stress drop $(\Delta \sigma)$ can be related as:

$$
f_{0 i}=4.9 \times 10^{6}\left(N_{R}(t)\right)^{-1 / 3} N^{1 / 3} \beta\left(\frac{\Delta \sigma}{M_{0}}\right)^{1 / 3}
$$

where $N_{R}(t)$ is the total number of subfaults ruptured at a time $t$, and the dynamic corner frequency for $i$ th subfault is represented by $f_{0 i} . H_{i}$ is the scaling factor responsible for conserving energy at the high frequency spectral level of subfaults, which is defined as:

$$
H_{i}=\left(N \frac{\sum_{f}\left(\frac{f^{2}}{1+\left(f / f_{0}\right)^{2}}\right)^{2}}{\sum_{f}\left(\frac{f^{2}}{1+\left(f / f_{0 i}\right)^{2}}\right)^{2}}\right)^{1 / 2}
$$

where $f_{0}$ is the corner frequency at the end of the rupture, i.e., the corner frequency of the entire fault, with $N_{R}(t)=N$. In the present study, the simulation code EXSIM developed by Motazedian and Atkinson (2005) is used. The code is a modified version of the original code FINSIM of Beresnev and Atkinson (1998).

\subsection{Scenario earthquakes}

The simulations are performed for four magnitudes: $M_{W}$ 5.8, 6.5, 6.8 and 7.1. The simulation parameters are summarized in table 1 . These scenario earthquakes are based on the 1997 Jabalpur earthquake $M_{W}$ 5.8, 1927 Son-Valley $M_{W}$ 6.5, and the estimated maximum earthquake of $M_{W}$ $6.8 \pm 0.3$ by Thingbaijam (2011) for the lower-crust zones in the peninsular India. The two scenarios of magnitude $-M_{W} 6.8$ and 7.1 , respectively correspond to the mean and +1 standard deviation of the estimated maximum earthquake. The tectonic structure of the Jabalpur earthquake is well constrained due to several studies, e.g., Bhattacharya et al (1998), Ramesh and Estabrook (1998) and Gahalaut et al (2004). Table 2 lists fault-plane solutions for the Jabalpur earthquake estimated by different researchers. The preferred solution for the nodal plane adapted for the present study, as listed in table 1, is that suggested by Saikia (2006) 
Table 1. Parameters used for strong ground motion simulations in Narmada South Fault are listed. The $M_{W} 5.8$ event is located at Jabalpur while rests of the events are located at Son Valley.

\begin{tabular}{|c|c|c|c|c|c|}
\hline Parameter & Value & & & & Reference note \\
\hline Strike $^{\circ}(\phi)$ & $70( \pm 10)$ & & & & Saikia (2006); \\
\hline $\operatorname{Dip}^{\circ}(\delta)$ & $68( \pm 03)$ & & & & Bhattacharya et al (1998) \\
\hline Stress (bars) & 270 & & & & Singh et al (1999a) \\
\hline Shear wave velocity (km/s) & 3.9 & & & & Singh et al (1999b) \\
\hline Crustal density $\left(\mathrm{g} / \mathrm{cm}^{3}\right)$ & 2.9 & & & & Manglik et al (2008) \\
\hline Pulsing area & $50 \%$ & & & & Atkinson and Boore (2006) \\
\hline$\kappa$ & 0.035 & & & & Boore and Joyner (1997) \\
\hline$Q_{S}$ & $800 f^{0.42}$ & & & & Singh et al (2004) \\
\hline Magnitude $\left(M_{W}\right)$ & 5.8 & 6.5 & 6.8 & 7.1 & \\
\hline Hypocentral depth (km) & 30.6 & 30.1 & 29.8 & 27.6 & Nath et al (2011) \\
\hline Rupture length (km) & 9 & 11 & 16 & 23 & Wells and Coppersmith (1994); \\
\hline Rupture width (km) & 6 & 11 & 15 & 20 & Nath and Thingbaijam (2011) \\
\hline $\begin{array}{l}\text { Fault location } \# \\
\text { (Long. }{ }^{\circ} \mathrm{E} \text {, Lat. }{ }^{\circ} \mathrm{N} \text { ) }\end{array}$ & $\begin{array}{l}80.042 \\
23.084\end{array}$ & $\begin{array}{l}80.893 \\
23.481\end{array}$ & $\begin{array}{l}80.841 \\
23.467\end{array}$ & $\begin{array}{l}80.760 \\
23.448\end{array}$ & \\
\hline
\end{tabular}

\# Top-corner of fault-rupture plane such that the dip is on the right-hand side.

Table 2. Fault plane solutions for 1997 Jabalpur earthquake for the preferred nodal plane; $M_{0}$ denotes seismic moment while GCMT and USGS stand for Global Centroid Moment Tensor and US Geological Survey.

\begin{tabular}{lcccc}
\hline Reference & $M_{0}($ dyne $\mathrm{cm})$ & Strike $^{\circ}(\phi)$ & Dip $^{\circ}(\delta)$ & Rake $^{\circ}(\lambda)$ \\
\hline GCMT & $5.8 \times 10^{24}$ & 61 & 70 & 73 \\
USGS & $5.3 \times 10^{24}$ & 75 & 70 & 90 \\
Bhattacharya et al $(1998)$ & $5.4 \times 10^{24}$ & 80 & 66 & 66 \\
Ramesh and Estabrook (1998) & $4.7 \times 10^{24}$ & 62 & 64 & 75 \\
\hline
\end{tabular}

and Bhattacharya et al (1998) in accordance to the spatial organization of seismicity. Since the fault-plane solution of the Son-Valley earthquake is unknown, we assign the focal mechanism of the Jabalpur earthquake to the scenario earthquakes for the simulation purpose.

The fault rupture dimensions are estimated using Wells and Coppersmith (1994): first, rupturearea and rupture-width, thereafter rupture-length since the relation between magnitude and rupturelength are known to be inconsistent. Nath and Thingbaijam (2011) observed that earthquake rupture-areas for reverse faulting earthquakes occurring in stable continental regions are smaller by a factor of 2 compared to those occurring in active regions as given by Wells and Coppersmith (1994) for magnitudes $M_{W}>6.4$. The earthquakes in the present study are of reverse faulting types and pertain to stable continental region. Hence, the rupture-area estimated by Wells and Coppersmith (1994) are corrected by factor of 2 for the magnitudes $M_{W}>6.4$. Following Singh et al (1999), the geometrical spreading function is taken as:

$$
\begin{aligned}
G(R) & =R^{-1} & & \text { for } R \leq R_{X} \\
& =\left(R R_{X}\right)^{-1 / 2} & & \text { for } R<R_{X}
\end{aligned}
$$

where $R$ is source-to-site distance in $\mathrm{km}$, and $R_{X}=$ 100. The windowing function of Saragoni and Hart (1974) along with $5 \%$ damping factor is used in the present analysis. Atkinson and Boore (2006) employed the fault pulsing area percentage of $50 \%$ for the finite-fault stochastic simulations in eastern North America. Similar value is considered since the present study region also comes under stable continental regions. On the other hand, slip distribution is taken to be random with the hypocenter placed at the bottom of the fault-rupture plane. In the present analysis, $\kappa$ is taken to be 0.035 as suggested by Boore and Joyner (1997) for generic rock sites. To simulate the reverse faulting, the hypocentral location is placed at position on the fault-plane defined by center of the rupture-length and about $80 \%$ of the rupture-width. Beresnev and Atkinson 
(a)
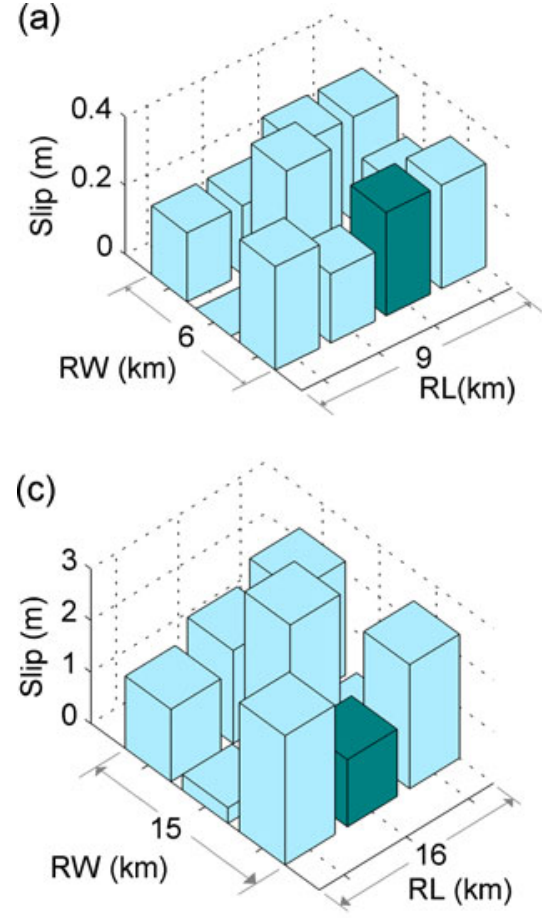

(b)

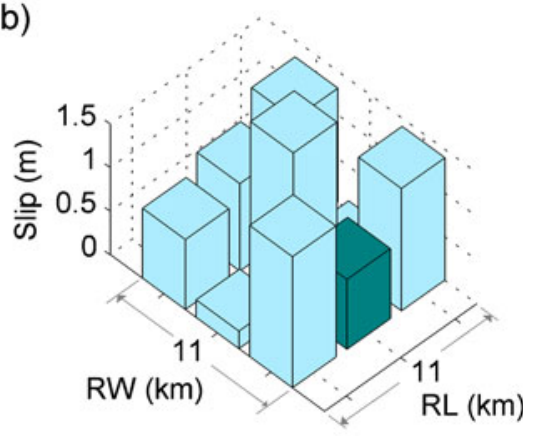

(d)

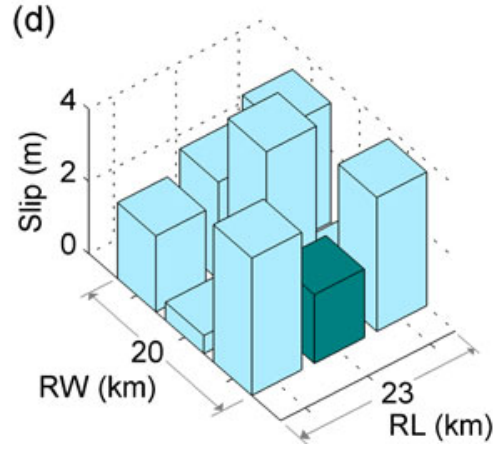

Figure 2. Sample slip-distributions across the projected rupture planes for the four simulated earthquakes of magnitude (a) $M_{W} 5.8$, (b) $M_{W} 6.5$, (c) $M_{W} 6.8$, and (d) $M_{W} 7.1$, respectively; the hypocenter is located in the sub-fault indicated by darkened block.

(2002) related the subfault size and the magnitude as follows:

$$
\log \Delta l=0.4 M_{W}-2 \quad \text { for } 4.0 \leq M_{W} \leq 8.0
$$

where $\Delta l$ is subfault length in $\mathrm{km}$. The relation is used in the present study to divide the faultrupture plane into subfaults. The slip distribution is randomly generated and the dispersion is initiated such that the rupture propagates upwards. Representative slip distributions are depicted in figure 2. The subfaults along the dip and strike respectively are implemented with $1 \mathrm{~km}^{2}$. The stress-drop estimates for the Jabalpur earthquake are observed to be higher than the average by Singh et al (1999a, 1999b). The authors estimated stress drop equivalent to 270 bars for the event and at the same time, observed that a stress drop of $\sim 420$ bars corresponds well to high-frequency level of the observed spectra. They suggested a value between 100 and 300 bars for lower crust earthquakes. On the other hand, Bhattacharya et al (1998) estimated relatively lower stress drop value of 68 bars for the event. Nevertheless, we adopt stress drop equal to 270 bars for the present simulations. Singh et al (1999a, $1999 \mathrm{~b}$ ) estimated the quality factor for the region to be equal to $Q=508 f^{0.48}$. However, Singh et al (2004) revised the estimation of $Q$ as equal to
$800 f^{0.42}$ for the Indian Shield region based on spectral attenuation of $\mathrm{Lg}$ waves from a dataset comprising of four earthquakes recorded in the distance range of $240-2400 \mathrm{~km}$. Although the present study deals with much smaller source-to-site distances, the new estimate is employed in the present study as it represents more reliable estimate for the Indian Shield region. Generic site response curves are often assumed for rock sites (e.g., Boore and Joyner 1997). In this perspective, the average site response model computed by Singh et al (2007) in the study region at Jabalpur is employed to provide

Table 3. Site amplification factors used for simulations at rock sites (adapted from Singh et al 2007).

\begin{tabular}{lc}
\hline Frequency $(\mathrm{Hz})$ & Amplification factor \\
\hline 0.12 & 0.6 \\
0.15 & 0.7 \\
0.30 & 1.0 \\
0.50 & 1.3 \\
1.00 & 2.1 \\
1.50 & 1.6 \\
2.00 & 1.3 \\
3.00 & 1.4 \\
4.00 & 1.6 \\
5.00 & 1.5 \\
10.00 & 2.0 \\
\hline
\end{tabular}


a generic but region-specific implementation. The authors estimated the transfer function in terms of horizontal-to-vertical $(\mathrm{H} / \mathrm{V})$ spectral ratio of S-waves of four local earthquakes recorded at Jabalpur, which is considered viable as the recording station is situated on Precambrian granite. The exact value of shear-wave velocity $\left(V_{S}\right)$ of the subsurface profile at the station is not known; however, National Earthquake Hazard Reduction Program (NEHRP) site class B or A (i.e., average shear wave velocity for $30 \mathrm{~m}$ upper-soil column $>760 \mathrm{~m} / \mathrm{s}$ ) can be assumed. The curve covers a frequency range of 0.13 to $12 \mathrm{~Hz}$ for rock site. Table 3 lists selected frequency and the corresponding amplification factor. The crustal amplifications for very hard rock conditions are observed to have factor with maximum of 1.15 times, which is close to unity (Boore and Joyner 1997). It is, therefore, ignored in the present study as such we have considered the site response. On the other hand, the fault-rupture depths are computed according to the hypocentral depth and the fault geometry. The duration parameter is represented as $T(R)=T_{0}+d R$, where $T_{0}$ is the source duration ( $T_{0}=$ fault length/rupture velocity), and $d$ is assigned a generic value of 0.1 following Beresnev and Atkinson (2002).

The simulations are performed on a grid with regular spacing of $\sim 22 \mathrm{~km}$ covering $300 \mathrm{~km}$ from the source location. Figure 3 depicts representative accelerograms for each earthquake simulated
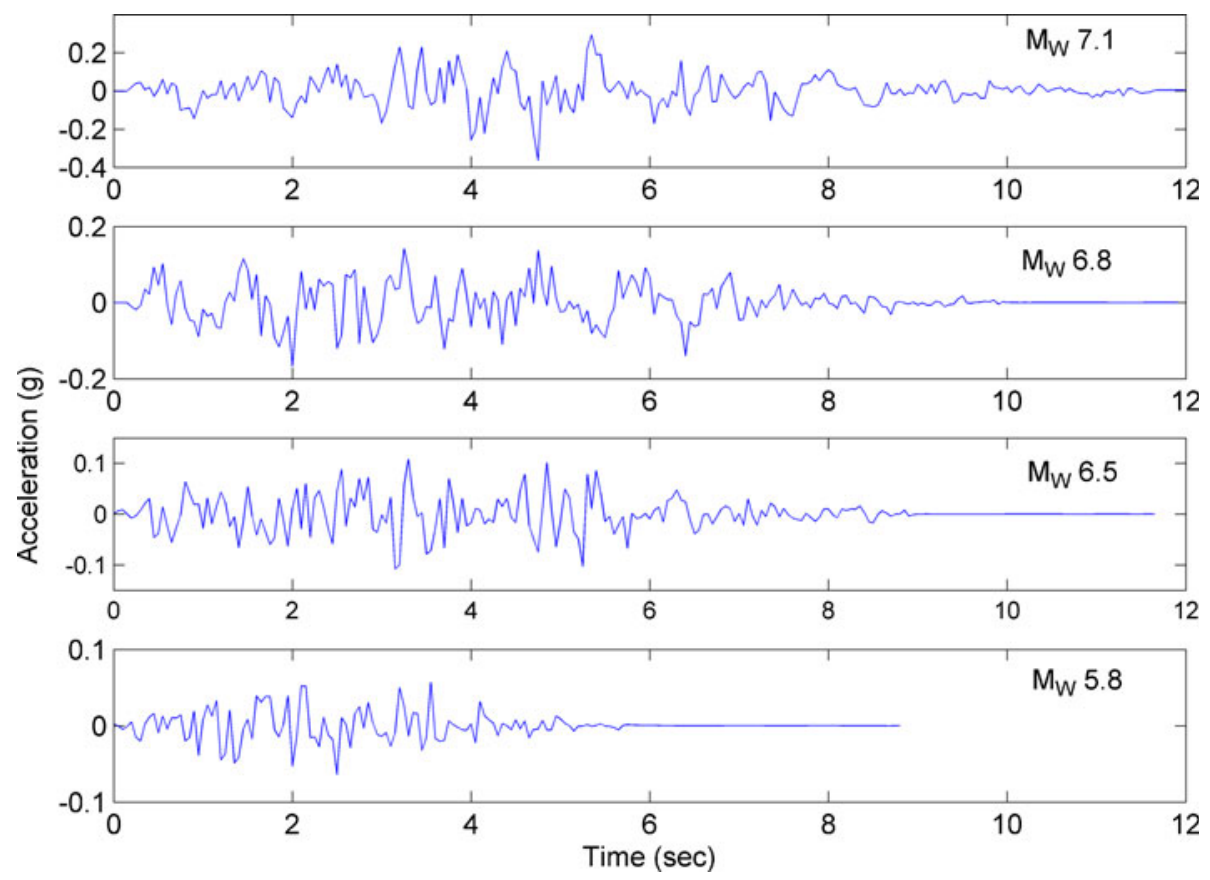

Figure 3. Representative simulated accelerograms for the four earthquakes at fault-rupture distance of $\sim 32 \mathrm{~km}$.

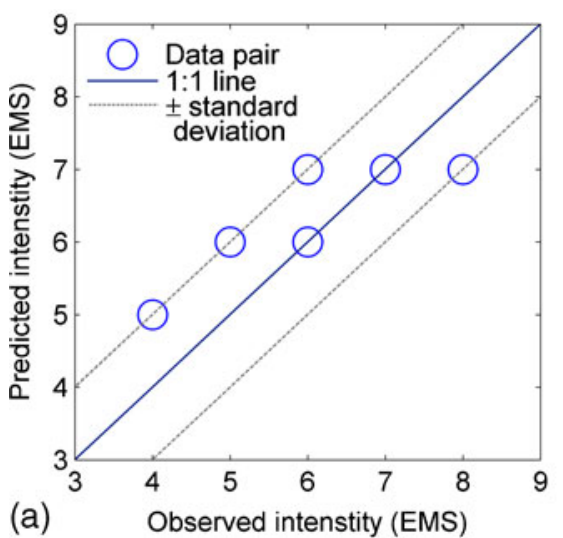

(a)

Observed intenstity (EMS)
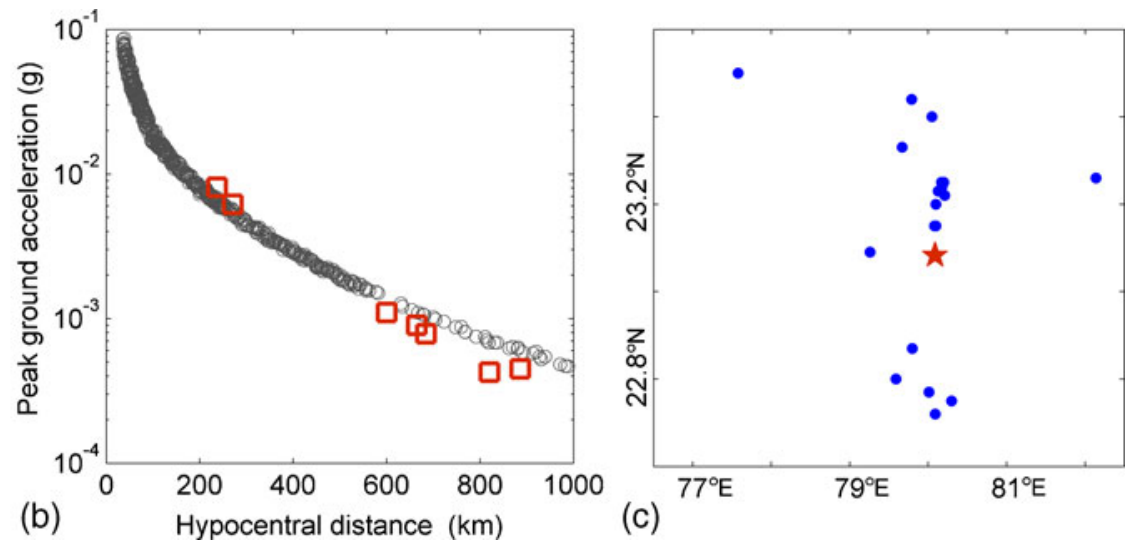

(c)

Figure 4. (a) Observed macroseismic intensity at rock sites with respect to simulated ones for 1997 Jabalpur earthquake of $M_{W}$ 5.8; the EMS intensity data are from Martin and Szeliga (2010). (b) Simulated PGA versus distance plot for the event; observed PGA (geometric mean of the horizontal components) are indicated with squares. (c) The spatial distribution of observation sites for the macroseismic intensity for the earthquake. Star indicates the epicenter. 
at a hypocentral distance of $\sim 36 \mathrm{~km}$. Simulations are performed 20 times each time with the slip distribution generated randomly to capture the epistemic uncertainty and results with maximum peak ground acceleration (PGA) are considered. The choice of 20 runs is according to Atkinson and Boore (2006). The simulated peak ground accelerations for the Jabalpur earthquake are calibrated with the observed intensity using PGA-EMS relation given by Nath and Thingbaijam (2011).
The intensity data in European Macroseismic Scale (EMS) is given by Martin and Szeliga (2010), and selected for rock sites as considered by Nath and Thingbaijam (2011). We observed reasonable conformity between the simulated and the observed intensity values within the bounds of \pm 1 standard deviation (figure 4a). The available observed ground-motion data are rather scanty. The PGA values as given by Singh et al (2003) are seen conforming reasonably to the simulated PGA

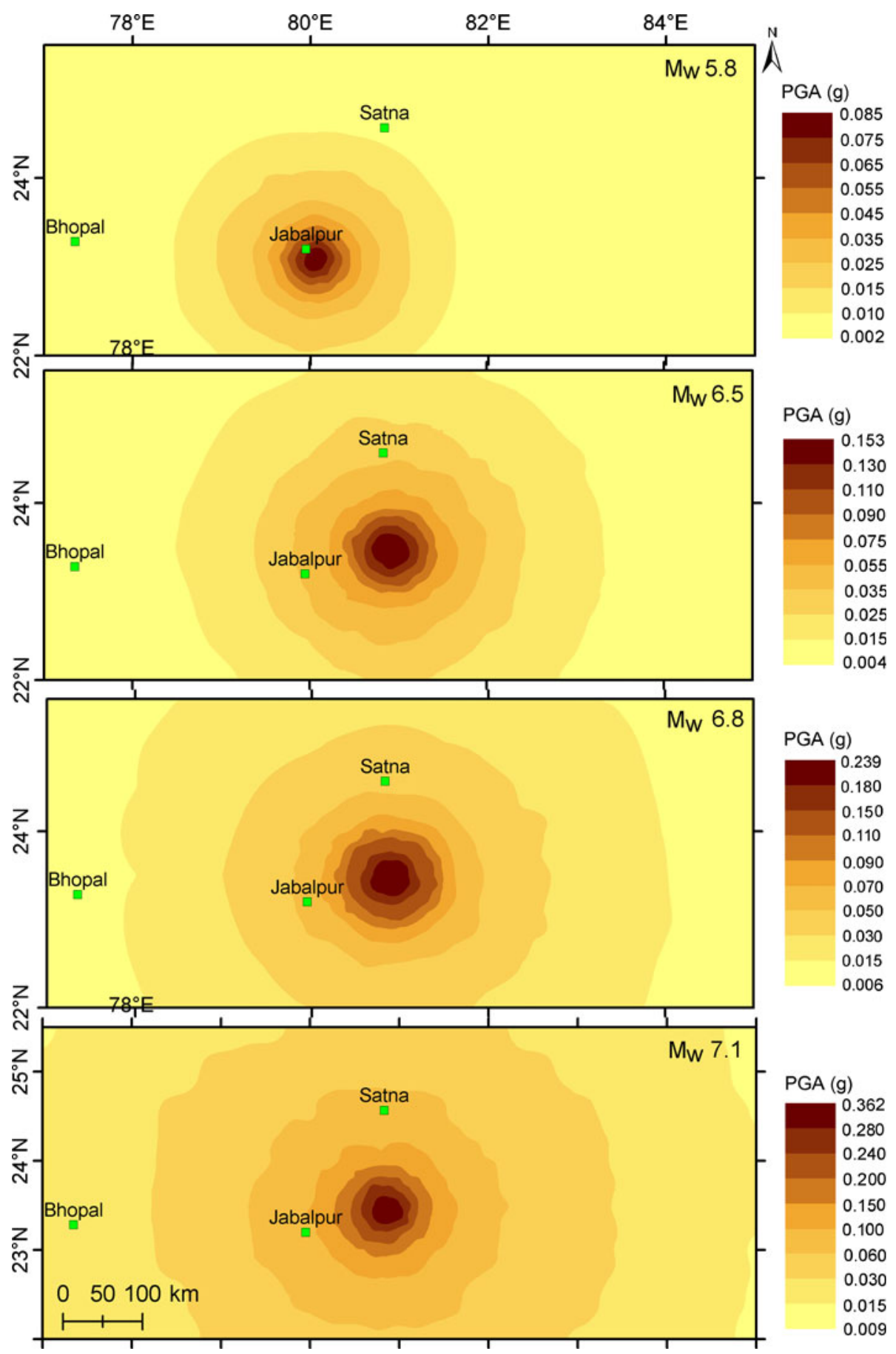

Figure 5. Spatial distributions of PGA corresponding to the four simulated earthquakes. 

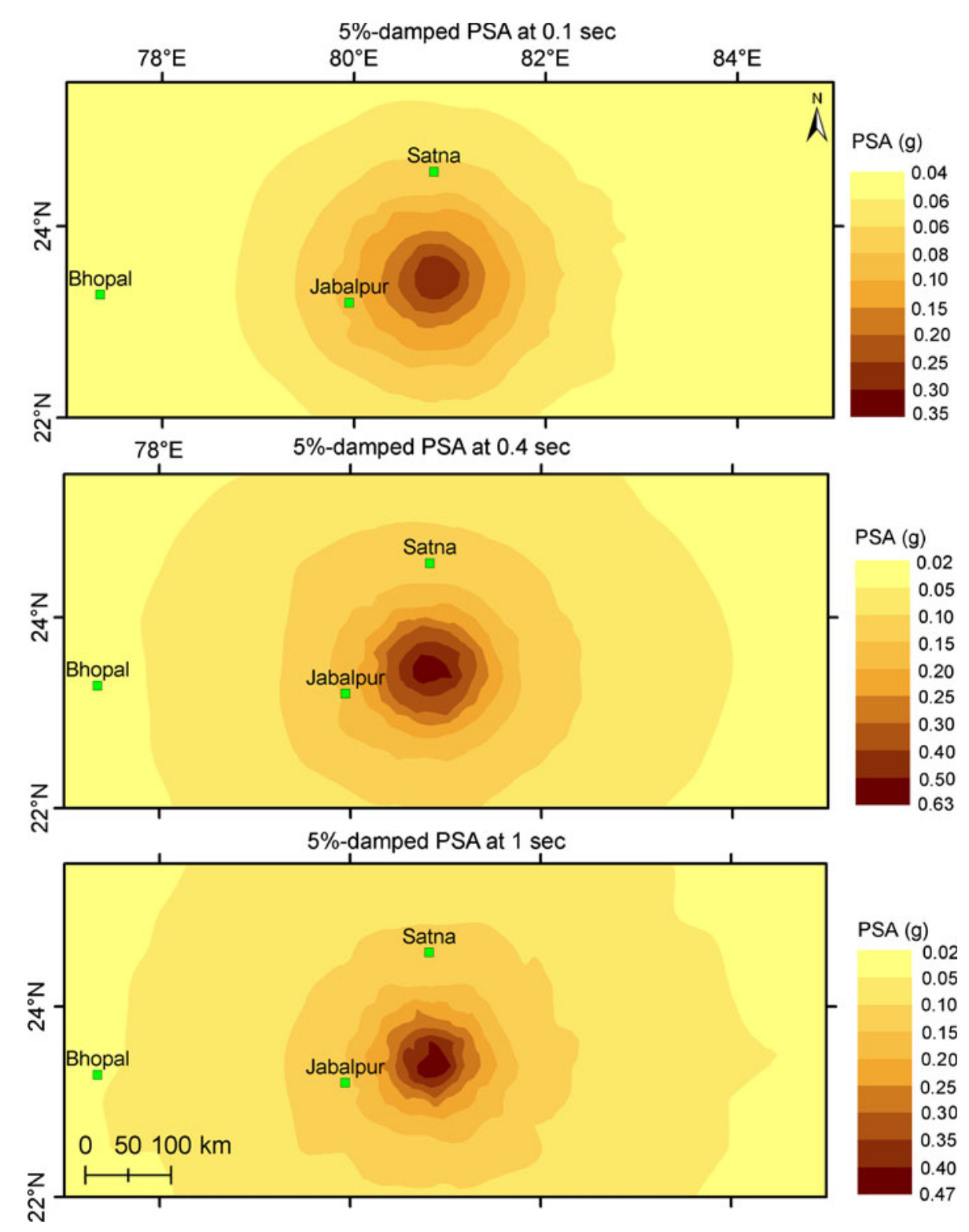

Figure 6. Spatial distributions of absolute 5\%-damped Pseudo-Spectral Acceleration (PSA) at 0.1, 0.4 and 1 s, respectively due to the maximum earthquake of $M_{W} 7.1$.

versus distance plot given in figure $4(\mathrm{~b})$. Comparison in terms of maps, i.e., between actual and simulated intensities is not viable due to difference in site conditions across the observed and predicted values. Figure 4(c) depicts the spatial distribution of the observation sites for the macroseismic intensity data. Most of the observed intensities are located at soil sites (not at rock sites considered for the simulations) and are likely to be implicated with site amplifications. The consistency of the predictions with observed intensities corroborates the viability of the finite-fault models presented here. The final results in terms of spatial distribution of PGA for each simulated event are depicted in figure 5. Furthermore, figure 6 depicts the spatial distribution of absolute Pseudo-Spectral
Acceleration (PSA) at spectral periods of $0.2 \mathrm{~s}$ and $1 \mathrm{~s}$, respectively for the scenario earthquake of magnitude $M_{W}$ 7.1. The periods correspond to short-period and long period, respectively. Damping factor of $5 \%$ has been considered. The simulated accelerograms and corresponding response spectra for the scenario earthquake at Jabalpur and Satna are depicted in figure 7.

\section{Discussion and conclusion}

The known historical earthquakes in the region are moderate ones. However, they caused significant damages suggesting considerable lack of awareness and inadequate seismic safety enforcement on the 
Son-Valley Scenario Earthquake of $\mathrm{M}_{\mathrm{W}} 7.1$
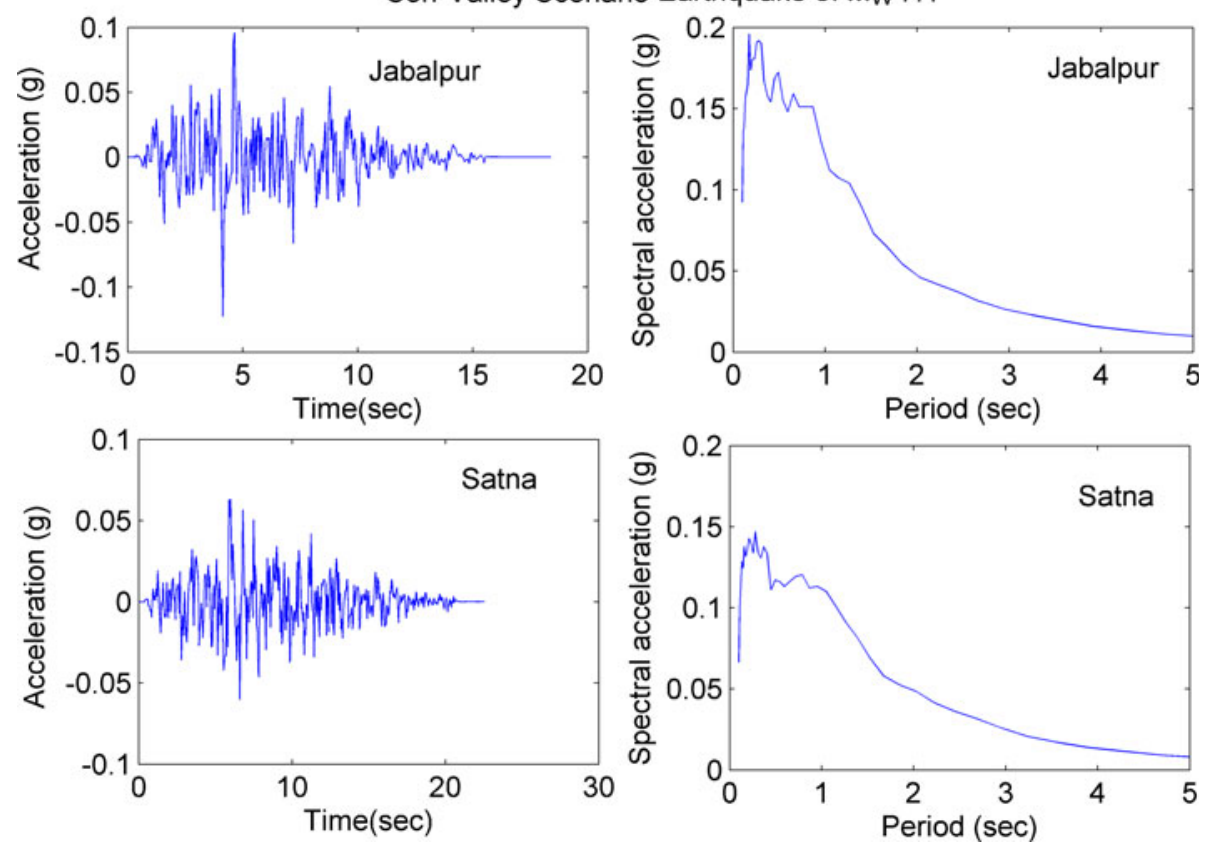

Figure 7. The simulated accelerogram and averaged 5\%-damped response spectra at Jabalpur and Satna, respectively for scenario earthquake of $M_{W} 7.1$.

constructions of built environment in the region. Three major events during 1927-1997 implicate a recurrence period of such events in the region to be about 30-40 years. It is, therefore, important to examine the possible effects of possible large events. In the present study, the finite fault models are developed according to four events: two historical and two estimated maximum earthquakes. The focal mechanism of events in the lower crust zone of the study region relevant for future large earthquakes is identified as predominantly reverse faulting type. The finite-fault models are developed and employed for stochastic simulations.

The simulations indicate that the 1997 Jabalpur $M_{W} \sim 5.8$ has rock-site PGA values ranging as high as $0.085 \mathrm{~g}$ while that of the 1927 Son-Valley $M_{W} \sim 6.5$ has maximum PGA value of $0.153 \mathrm{~g}$. These observations suggest that there is an exceedance of about $50 \%$ increment of the peak ground acceleration with difference of 0.7 magnitude units. The study region comes under zone 3 of seismic zonation map of India (BIS 2002) with the ascribed PGA for maximum credible earthquake of about $0.16 \mathrm{~g}$. The predicted PGA distribution for the $M_{W} 6.8$ scenario earthquake yields maximum peak ground acceleration of $0.24 \mathrm{~g}$. This suggests that BIS (2002) considerably underestimates prevailing hazard in the region. Furthermore, the projected maximum earthquake of $M_{W} 7.1$ indicates an increase of about $25 \%$ in the PGA distribution with a maximum value of $0.36 \mathrm{~g}$. Likely high seismic demands on the buildings from future strong earthquakes can be inferred from the spectral accelerations derived from the scenarioearthquakes in the regions close to the source, i.e., within $50 \mathrm{~km}$ rupture distance. The spatial distributions of the spectral accelerations also indicate that the future earthquakes in the Son-Valley could affect wide region. Similar ground-motions are observed in Jabalpur and Satna towns, which are located at distance of nearly $180 \mathrm{~km}$ apart, and at approximate hypocentral distances of 120 and $97 \mathrm{~km}$, respectively from the source.

The present analysis accomplishes finite-fault modelling of strong earthquakes in the Narmada South Fault based on stochastic simulations. The study may be extended to cover wider range of magnitudes. The study region experiences earthquake infrequently, and therefore, development of synthetic data is envisaged to achieve the ground-motion predictions. The present study is a forerunner of extensive analysis of deterministic and probabilistic seismic hazard analysis of the region.

\section{Acknowledgements}

The author is grateful to Dr P Dewangan (Associate Editor), and three anonymous reviewers for their critical comments and suggestions that significantly improved the present work. 


\section{References}

Anderson J G and Hough S E 1984 A model for the shape of the Fourier amplitude spectrum of acceleration at high frequencies; Bull. Seismol. Soc. Am. 74 1969-1993.

Atkinson Gail M and Boore D M 2006 Earthquake groundmotion prediction equations for eastern North America; Bull. Seismol. Soc. Am. 96 2181-2205.

Beresnev I A and Atkinson G M 1998 FINSIM - a FORTRAN program for simulating stochastic acceleration time histories from finite faults; Seis. Res. Lett. 69 27-32.

Beresnev I A and Atkinson G M 2002 Source parameters of earthquakes in eastern and western North America based on finite-fault modeling; Bull. Seismol. Soc. Am. 92 695-710.

Bhattacharya S N, Ghose A K, Suresh G, Baidya P R and Saxena R C 1998 Source parameters of Jabalpur earthquake of 22 May 1997; Curr. Sci. 73 855-863.

Bilham R, Bendick R and Wallace K 2003 Flexure of the Indian plate and intraplate earthquakes; Proc. Indian Acad. Sci. (Earth Planet Sci.) 112 1-14.

BIS 2002, IS1893-2002 (Part 1): Indian Standard Criteria for Earthquake Resistant Design of Structure. Part 1: Resistant Provisions and Buildings; Bureau of Indian Standards, New Delhi.

Boore D M 1983 Stochastic simulation of high-frequency ground motions based on seismological models of the radiated spectra; Bull. Seismol. Soc. Am. 73 1865-1894.

Boore D M and Joyner W B 1997 Site amplifications for generic rock sites; Bull. Seismol. Soc. Am. 87 327-341.

Dasgupta S, Pande P, Ganguly D, Iqbal Z, Sanyal K, Venkatraman N V, Dasgupta S, Sural B, Harendranath L, Mazumadar K, Sanyal S, Roy A, Das L K, Misra P S and Gupta H 2000 Seismotectonic atlas of India and its environs; Geol. Surv. India.

Gahalaut V K, Rao V K and Tewari H C 2004 On the mechanism and source parameters of the deep crustal Jabalpur earthquake, India, of 1997 May 21: Constraints from aftershocks and changes in static stress; Geophys. J. Int. 156 345-351.

Kayal J R 2000 Seismotectonic study of the two recent SCR earthquakes in central India; J. Geol. Soc. India 55 123-138.

Kayal J R 2008 Microearthquake seismology and seismotectonics of south Asia, 1st edn (India: Springer Verlag and Capital Publishing Company), ISBN: 978-1-4020-8179-8.

Mandal P, Rastogi B K and Harsh K Gupta 2000 Recent Indian earthquakes; Curr. Sci. 79 1334-1346.

Manglik A, Thiagarajan S, Mikhailova A V and Rebetsky Y 2008 Finite element modelling of elastic intraplate stresses due to heterogeneities in crustal density and mechanical properties for the Jabalpur earthquake region, central India; J. Earth Syst. Sci. 117 103-111.

Martin S and Szeliga W 2010 A catalog of felt intensity data for 589 earthquakes in India from 1636 to 2009; Bull. Seismol. Soc. Am. 100 562-569.

Motazedian D and Atkinson G M 2005 Stochastic finitefault modeling based on a dynamic corner frequency; Bull. Seismol. Soc. Am. 95 995-1010.

Nath S K and Thingbaijam K K S 2011 Peak ground motion predictions in India: An appraisal for rock sites; J. Seismol. 15 295-315.
Nath S K, Raj A, Thingbaijam K K S and Kumar A 2009 Ground motion synthesis and seismic scenario in Guwahati city - a stochastic approach; Seismol. Res. Lett. 80 233-242.

Nath S K, Thingbaijam K K S and Ghosh S K 2011 A unified earthquake catalogue for South Asia covering the period 1900-2008; Data accessible at http://www.earthqhaz.net/sacat/.

Rajendran C P, Rajendran K and John B 1996 The 1993 Killari (Latur), Central India, Earthquake: An example of fault reactivation in the Precambrian Crust; Geology 24 651-654.

Ramesh D S and Estabrook C H 1998 Rupture histories of two stable continental region earthquakes of India; $J$. Earth Syst. Sci. 107 L225-L233.

Rao B R and Rao V K 2006 Influence of fluids on deep crustal Jabalpur earthquake of 21, May 1997: Geophysical evidences; J. Seismol. 10 301-314.

Saikia C K 2006 Modeling of the 21 May 1997 Jabalpur earthquake in central India: Source parameters and regional path calibration; Bull. Seismol. Soc. Am. 96 1396-1421.

Saragoni G R and Hart G C 1974 Simulation of artificial earthquakes; Earthquake Eng. Struct. Dyn. 2 249-267.

Singh S K, Ordaz M, Dattatrayam R S and Gupta H K 1999a A spectral analysis of the 21 May 1997, Jabalpur, India, earthquake $\left(M_{W}=5.8\right)$ and estimation of ground motion from future earthquakes in the Indian Shield Region; Bull. Seismol. Soc. Am. 89 1620-1630.

Singh S K, Dattatrayam R S, Shapiro N M, Mandal P, Pacheco J F and Midha R K 1999b Crustal and upper mantle structure of peninsular India and source parameters of the 21 May 1997, Jabalpur earthquake $\left(M_{W}=\right.$ 5.8): Results from a new regional broadband network; Bull. Seismol. Assoc. Am. 89 1631-1641.

Singh S K, Bansal B K, Bhattacharya S N, Pacheco J F, Dattatrayam R S, Ordaz M, Suresh G, Kamal and Hough S E 2003 Estimation of ground motion for Bhuj (26 January $2001 ; M_{W}$ 7.6) and for future earthquakes in India; Bull. Seismol. Assoc. Am. 93 353-370.

Singh S K, Garcia D, Pacheco J F, Valenzuela R, Bansal B K and Dattatrayam R S 2004 Q of the Indian shield; Bull. Seismol. Soc. Am. 94 1564-1570.

Singh S K, Pimprikar S D, Bansal B K, Pacheco J F, Dattatrayam R S and Suresh G 2007 An analysis of the $M_{W} 4.7$ Jabalpur, India, Earthquake of 16 October 2000: Toward ground-motion estimation in the region from future events; Bull. Seismol. Soc. Am. 97 14751485 .

Thingbaijam K K S 2011 Synoptic modeling for probabilistic seismic hazard analysis of India; Unpublished PhD thesis, Indian Institute of Technology Kharagpur, India.

Ugurhan B and Askan A 2010 Stochastic strong ground motion simulation of the 12 November 1999 Düzce (Turkey) earthquake using a dynamic corner frequency approach; Bull. Seismol. Soc. Am. 100 1-27.

Wells D L and Coppersmith K J 1994 New empirical relationships among magnitude, rupture length, rupture width, rupture area, and surface displacement; Bull. Seismol. Assoc. Am. 84 974-1002. 